\title{
STUDI TENTANG KEPUASAN KONSUMEN DI TOKO EMAS PUSAKA SUKOREJO KENDAL
}

\author{
RA Nur Amalina, I Made Sukresna, J. Sugiharto \\ Magister Manajemen, Fakultas Ekonomika dan Bisnis, Universitas Diponegoro
}

\begin{abstract}
ABSTRAK
Penelitian ini bertujuan untuk menganalisis pengaruh kualitas barang emas dan kualitas layanan terhadap WOM (Word Of Mouth) dengan menggunakan kepuasan konsumen sebagai variabel mediator (intervening) studi pada toko emas pusaka mas Sukorejo Kendal. Kualitas barang emas merupakan hal yang menjadi pertimbangan konsumen dalam melakukan pembelian pada Toko emas pusaka Sukorejo Kendal. Responden dalam penelitian ini adalah konsumen yang melakukan transaksi di toko emas pusaka mas Sukorejo Kendal. Data dikumpulkan melalui metode kuisioner yang diisi secara mandiri oleh 155 responden yang dipilih dengan metode non probability sampling dimana responden telah melakukan pembelian atau transaksi di toko emas pusaka mas Sukorejo Kendal. Metode analisis yang digunakan adalah analisis Structural Equation Modelling (SEM) yang dijalankan dengan program AMOS. Hasil pengujian hipotesis dengan SEM menunjukkan bahwa: 1. Kualitas barang emas berpengaruh positif terhadap kepuasan konsumen, 2. Kualitas layanan berpengaruh positif terhadap kepuasan konsumen, 3. Kepuasan konsumen berpengaruh positif dan signifikan terhadap WOM 4. Kualitas layanan berpengaruh positif terhadap WOM studi pada toko emas pusaka mas Sukorejo Kendal.
\end{abstract}

Kata Kunci: Kualitas produk, Toko Emas, Kualitas Layanan, Kepuasan Konsumen, Word Of Mouth (WOM).

\section{PENDAHULUAN}

Perekonomian Indonesia mengalami kemajuan dalam teknologi digital pada beberapa sektor bisnis. Perubahan kemajuan ekonomi digital mengubah beberapa sector bisnis beralih dari offline ke online, khususnya dalam pemakaian transaksi uang yang telah berubah menjadi digital money sebagai alat tukar yang praktis. 
Seiring berkembangnya perekonomian, uang semakin bersifat maya baik fisik maupun nilainya. Namun emas pada ekonomi digital saat ini memiliki nilai yang tidak berubah (hedging), emas merupakan sarana lindung nilai yang baik ketika kondisi ekonomi sedang krisis, semakin besar krisis harga emas akan semakin bernilai. Untuk menghindari krisis perekonomian / inflasi emas masih dipilih oleh masyarakat sebagai produk pembelian investasi (Kusnandar, 2010).

Menurut Kusnandar (2010) emas merupakan logam yang padat, mengkilat, dan lentur dibandingkan dengan logam mulia lainnya. Emas dibagi menjadi dua bentuk, pertama emas dalam bentuk perhiasan seperti kalung, cincin, giwang, anting, bandul dan gelang. Kedua emas dalam bentuk batangan (antam). Nilai emas memiliki beberapa keuntungan diantaranya tahan lama (durable), tidak ada batas expired, mudah diuangkan, sebagai alat tukar dan apabila produk emas rusak masih bernilai. Sehingga tidak heran ketika produk emas menjadi daya tarik masyarakat dari berbagai kalangan kelas menengah, bawah dan atas.

Berdasarkan hasil analisis gold price chart tahun 2017 yang dikeluarkan oleh goldprice.org, harga emas di Indonesia pada tahun 2013 sebesar 16.500 .000 rupiah meningkat pada tahun 2017 sebesar 17.500 .000 rupiah. Jumlah ini cenderung meningkat tiap tahunnya dan didukung dengan adanya pajak yang dikeluarkan pemerintah melalui PMK Nomor 34/PMK.010/2017 bahwa emas yang akan dibeli dikenakan pajak sebesar $0.45 \%$. Namun dari hasil wawancara yang dilakukan oleh Feby Novalius selaku wartawan okezone.com jumat 6 Nov 2017, hal ini tidak menyusutkan konsumen dalam melakukan pembelian produk emas.

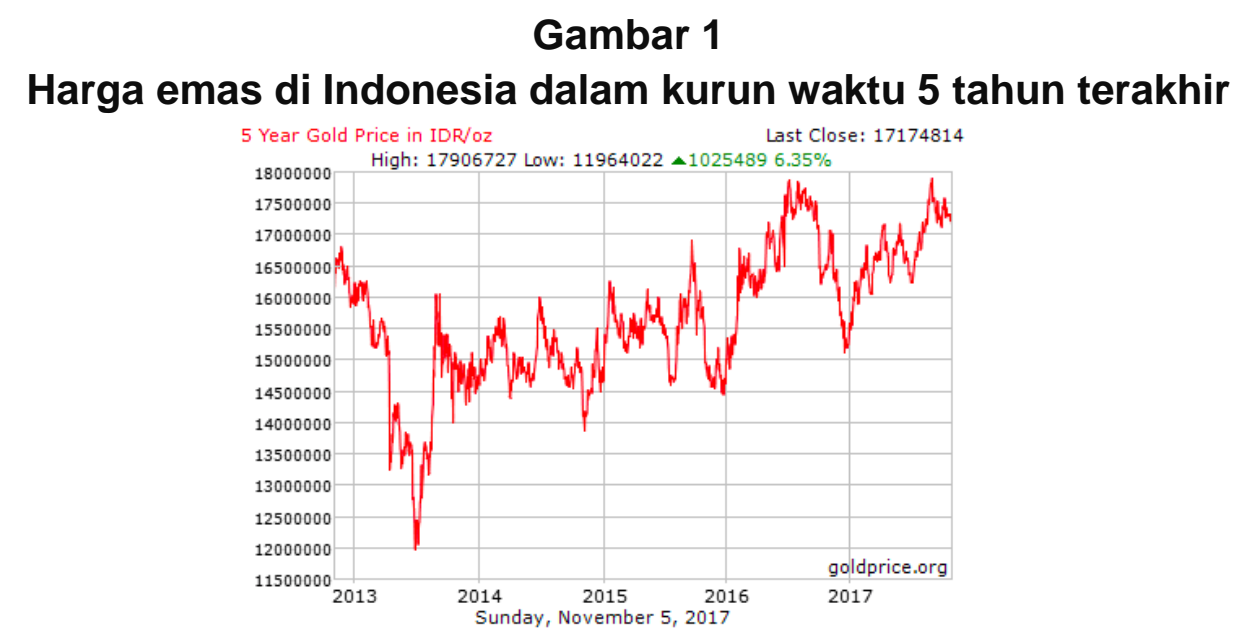

Sumber: Goldprice,org. (2017)

Kebiasaan konsumen Indonesia untuk melakukan pembelian perhiasan emas sebagai gaya hidup lifestyle mendorong pertumbuhan perhiasan emas meningkat sebanyak 10 - 20 persen pada tahun 2015 - 2017 (Kontan.co.id, 2018). 
Perhiasan emas ini diprediksi akan tetap meningkat sebesar 7.8 persen pada tahun 2016 -2021 karena adanya permintaan pasar yang menunjukkan tren kenaikan. Hal ini didorong oleh dua factor ekonomi dan factor daya beli, dimana konsumen lebih tertarik membeli barang secara maksimal untuk memperindah penampilan dan berinvestasi.

Semakin banyaknya pebisnis perhiasan emas, persaingan akan lebih ketat, khususnya di wilayah Kabupaten Kendal yang memiliki banyak kompetisi toko emas. Pada situs BPS kabupaten Kendal terdapat 20 kecamatan yang berada di Kabupaten Kendal, terdapat kurang lebih 33 toko emas yang tercatat pada pencarian di google.com. Sementara itu, jumlah penduduk kecamatan Sukorejo menurut BPS.co.id pada tahun 2016 adalah sebanyak 57.863 jiwa. Tentunya tidak semua penduduk Sukorejo mengunjungi toko emas yang ada di kecamatannya. Oleh sebab itu dibutuhkan pengelompokan pengunjung toko emas untuk memudahkan pengelola toko emas dalam menentukan sasarannya. Menurut Survei 30 responden yang melakukan pembelian di toko emas Pusaka Sukorejo, secara garis besar pengunjung dapat dikelompokkan pada Tabel 1.

Tabel 1

Karakteristik Pengunjung Pembelian Emas Berdasarkan Kelompok Usia

\begin{tabular}{ll}
\hline \multicolumn{1}{c}{ Kelompok Usia } & \multicolumn{1}{c}{ Karakteristik } \\
\hline$<20$ tahun & $\begin{array}{l}\text { Emas putih, Emas muda, Emas dengan model } \\
\text { luxury brand, Perhiasan emas yang berwarna, } \\
\text { Model emas yang kekinian }\end{array}$ \\
& $\begin{array}{l}\text { Emas dengan model luxury brand, Emas berwarna, } \\
\text { Emas Antam, Emas dengan model uptodate, Emas } \\
\text { yang dapat ditukar di mana saja }\end{array}$ \\
& Tidak penting model yang penting perhiasan emas \\
& dan dapat dilakukan tukar menukar dimana saja
\end{tabular}

Sumber: Responden Toko Emas Pusaka Sukorejo, 2017

Pengelola toko emas tidak hanya berhenti pada produk emas saja. Dibutuhkan WOM agar konsumen mengetahui mengenai toko emas yang cocok dan nyaman untuk di kunjungi. WOM memiliki pengaruh terhadap rasa percaya konsumen terhadap review konsumen lainnya mengenai suatu toko yang direkomendasikan (suprapti, 2010:274). Namun pada toko emas pusaka Sukorejo Kendal memiliki beberapa keluhan dari 30 responden yang telah melakukan pembelian di toko mas tersebut, seperti pelayanan yang kurang baik, fasilitas yang 
kurang memadai dsb. Sehingga konsumen kurang merasa puas terhadap layanan yang diberikan toko tersebut.

Tabel 2

Daftar Keluhan Konsumen Pusaka Mas

\begin{tabular}{|c|c|}
\hline $\begin{array}{c}\text { Pelanggan berdasarkan } \\
\text { usia }\end{array}$ & Jenis Keluhan \\
\hline $17-19$ & $\begin{array}{l}\text { Model kurang uptodate khususnya emas putih } \\
\text { Panas tidak ada AC } \\
\text { Model emas yang unik dan impor hanya beberapa }\end{array}$ \\
\hline $20-24$ & $\begin{array}{l}\text { Pelayanannya tidak ramah } \\
\text { Tidak ada ruang tunggu atau tempat duduk untuk } \\
\text { menunggu } \\
\text { Barang baru disimpan pada stock dalam dan tidak } \\
\text { dikeluarkan di etalase toko }\end{array}$ \\
\hline $25-55$ & $\begin{array}{l}\text { Berdesak - desakan (toko sempit) } \\
\text { Beberapa emas model baru disimpan dan tidak } \\
\text { dikeluarkan semua sehingga harus tanya dulu } \\
\text { kepada sales toko } \\
\text { Pelayanan kurang ramah }\end{array}$ \\
\hline
\end{tabular}

Sumber: Kuisioner Konsumen Pusaka Mas, 2017

Daftar keluhan konsumen ini didapat dari kuisioner studi pendahuluan sebanyak 30 responden yang telah melakukan transaksi di toko emas pusaka mas Sukorejo, dengan rentang usia $17-55$ tahun. Keluhan konsumen ini muncul karena konsumen yang melakukan transaksi pembelian di toko emas kurang puas terhadap pelayanan toko pusaka mas tersebut, dimana disebutkan bahwa beberapa konsumen menyatakan bahwa barang emas model baru tidak dikeluarkan dari etalase toko namun disimpan oleh pemilik toko dan konsumen harus aktif atau menunggu sales toko untuk menginformasikan barang baru. Tanpa adanya layanan yang baik, konsumen tidak akan puas dikarenakan konsumen memiliki ekpetasi tinggi yang harus dipenuhi.

Berdasarkan latar belakang yang sudah disampaikan sebelumnya, terdapat peningkatan jumlah toko emas di kabupaten Kendal. Pertumbuhan ini sangat penting karena kontribusinya terhadap pemasukan kota Kabupaten Kendal khususnya Kecamatan Sukorejo. Namun bila pelaku bisnis tidak memperhatikan kualitas barang, layanan dan kepuasan konsumen maka usia bisnis emas ini akan tersaingi oleh toko emas lainnya. Melalui penelitian ini, diharapkan adanya efek yang baik dari kualitas barang, dan kualitas layanan yang nantinya akan meningkatkan kepuasan konsumen yang berdampak kepada WOM. 
Berdasarkan fenomena bisnis yang dijelaskan didalam latar belakang, peningkatan jumlah toko emas yang tinggi dapat menimbulkan persaingan yang ketat, juga adanya keluhan konsumen yang dapat mengurangi kepercayaan konsumen yang nantinya dapat berdampak negative WOM. Dibutuhkan penanganan dan pemahaman yang baik terhadap kualitas barang dan kualitas layanan yang dilakukan untuk memantapkan kepuasan konsumennya. Dengan memakai model penelitian yang tidak sama dengan penelitian terdahulu, maka masalah yang akan dikaji adalah "bagaimana meningkatkan kualitas barang dan kualitas layanan untuk meningkatkan WOM". Adapun tujuan dilakukan penelitian ini adalah sebagai berikut: (1) Agar dapat menganalisis pengaruh kualitas barang terhadap kecenderungan kepuasan konsumen pada toko emas pusaka Sukorejo Kendal; (2) Untuk dapat menganalisis pengaruh service quality terhadap kecenderungan kepuasan konsumen pada toko emas pusaka Sukorejo Kendal; (3) Untuk dapat menganalisis pengaruh kualitas layanan terhadap WOM pada toko emas pusaka Sukorejo Kendal; (4) Untuk dapat menganalisis pengaruh cutomer satisfaction terhadap WOM pada toko emas pusaka mas Sukorejo Kendal.

\section{TELAAH PUSTAKA}

\section{Word of Mouth (WOM)}

Houshang Taghizadeh (2012) dalam jurnalnya mengatakan WOM merupakan komunikasi konsumen tentang barang dan jasa dimana komunikasi WOM memiliki kekuatan persuasif yang kuat. Dijelaskan juga bahwa WOM adalah suatu komunikasi, nasihat dan saran yang telah mengalami layanan barang atau jasa kepada orang lain agar konsumen mendapatkan kepercayaan atau informasi terhadap suatu jasa atau barang secara efektif dibandingkan komunikasi yang diberikan oleh perusahaan.

Katz dan Lazarsfeld (2011) dalam jurnalnya mengatakan bahwa WOM lebih efektif dari media promosi seperti surat kabar, TV, iklan, majalah, personal selling, radio dan lain lain dalam mempengaruhi konsumen untuk berganti merek atau loyal terhadap merek tertentu. Hal ini memperlihatkan WOM lebih kredibel dimana konsumen cenderung mereview suatu produk dahulu sebelum mempersuasif konsumen lainnya dalam melakukan pembelian suatu produk atau jasa yang didorong kebutuhan atau keinginan. Misal seorang ibu - ibu yang melakukan transaksi pembelian emas, pada saat melakukan pembelian emas penjual toko sangat ramah dan informatif dalam melayani ibu tersebut, sehingga ibu tersebut merasa puas, kemudian melakukan WOM kepada komunitasnya yang terdiri dari 20 orang. 
Berdasarkan hal itu, dapat diambil kesimpulan bahwa WOM dapat mempengaruhi pola pikir konsumen dengan harapan konsumen tersebut puas dan memberikan sanggahan positif atau respon positif terhadap barang ataupun jasa yang telah dilakukannya. Namun untuk membuat WOM positif harus ada kualitas produk atau kualitas layanan yang dapat diterima oleh konsumen.

\section{Kepuasan Konsumen}

Pada peneliti terdahulu mengatakan bahwa kepuasaan konsumen merupakan sebuah proses respon emosional, respon kognitif murni, ringkasan total psikologis, respon pemenuhan atau evaluasi pembelian keseluruhan (Oliver, 1981 dan Fornell, 1992). Namun sebuah penelitian terbaru mengenai kepuasan konsumen menggambarkan ringkasan dari respon afektif yang bervariasi dalam intensitas yang berfokus pada pilihan produk, pembelian dan konsumsi (Giese dan Cote, 2000).

Kepuasan Konsumen memiliki pengaruh langsung terhadap WOM dan dikemukakan bahwa ketika seorang konsumen puas dengan layanan atau produk dari suatu perusahaan, hal ini akan memiliki kecenderungan untuk setia pada perusahaan sangat tinggi karena didorong pelanggan potensial dan positif konsumen. Dengan demikian WOM merupakan indicator utama yang mendukung kepuasan konsumen dengan 4 dimensi indicator yaitu, (1) altruism (keinginan untuk membantu orang lain), (2) Instrumentalism (keinginan menginformasikan hal positif kepada orang lain, atau memberikan informasi yang cerdas), (3) ego defense, (4) respon kognitif (Dichter 1966 dan Arndt 1967).

\section{Kualitas Layanan}

Kualitas layanan merupakan perilaku kinerja jasa yang memiliki kriteria sesuai dengan harapan konsumen yang secara langsung berhubungan dengan kepuasan konsumen (Bolton dan Drew, 1991). Kualitas layanan merupakan factor penting untuk perusahaan khususnya pada toko pusaka mas Sukorejo Kendal agar tidak kalah bersaing dengan perusahaan emas lainnya. Menurut David gardin dan Leod (2007) kualitas layanan memiliki 7 dimensi yaitu kinerja, features, keandalan, daya tahan (durability), kemudahan perbaikan, keindahan, persepsi.

Penelitian terdahulu menerapkan metode SERVQUAL, kualitas pelayanan yang diharapkan konsumen adalah perbedaan antara kinerja actual dan harapan yang diterima sehingga akan diperoleh nilai gap (kesenjangan) dari masing masing atribut dimensi yang berbeda. (Santos Rodrigue et al, 2010). SERVQUAL dipengaruhi empat factor yaitu nyata, tidak berwujud (perhatian kepada konsumen), efisiensi kinerja terhadap perusaan dan efisien kinerja terhadap perusahaan. Dengan adanya metode SERVQUAL diharapkan kualitas pelayanan dapat 
menyesuaikan diri dimanapun berada, dan dapat menghindari kesalahan yang ada pada perusahaan baik secara perspektif internal maupun perspektif eksternal.

\section{Kualitas Barang}

Kualitas barang adalah persepsi konsumen terhadap kualitas keseluruhan atau keunggulan dari barang yang berhubungan dengan tujuan yang telah ditetapkan secara relative dan alternatif (Ehsani, 2015). Sedangkan Kotler dan Armstrong, 2012 mengemukakan bahwa kualitas produk merupakan karakteristik produk atau jasa yang sesuai kebutuhan guna memuaskan konsumen. Kotler 2012, juga mengemukakan kualitas produk memiliki tujuh indicator diantaranya yaitu, estetika, persepsi kualitas, daya layanan, fitur, kinerja, kehandalan, dan kepatuhan.

Pada penelitian terdahulu kualitas produk tidak ditinjau oleh sudut pandang perusahaan, penentuan arah kualitas produk yang utama ditinjau dari perspektif konsumen sehingga munculnya dua factor kualitas produk yang diharapkan konsumen dan kualitas produk yang dirasakan dengan harapan kualitas produk dapat menimbulkan kepuasan konsumen. Misalnya pada toko pusakamas terdapat produk emas yang berwarna kuning, namun banyaknya mindset generasi muda kuning = tua maka perusahaan emas memberikan alternative pilihan produk emas dengan warna warni sehingga tercipta karakteristik produk yang memuaskan konsumen.

\section{Pengaruh Antar Variabel}

\section{Pengaruh Kualitas Barang Emas terhadap Kepuasan Konsumen}

Kualitas barang emas memiliki karakteristik barang yang berbeda sesuai dengan kondisi, yang mana produk dibuat sesuai kebutuhan guna memenuhi harapan konsumen. (Kotler, 2012). Produk akan dinilai berkualitas apabila sesuai dengan kebutuhan pasar seperti barang fisik, ide, kegunaan produk, tempat, unik dsb. Konsumen yang melakukan pembelian suatu produk berkualitas pasti akan merasa puas, sesuai dan senang, hal ini memberikan nilai tambah terhadap suatu produk.

Kualitas produk yang sesuai ditawarkan akan berdampak positif terhadap kepuasaan konsumen, dalam penelitian Ismail Razak, 2016 mengasumsikan bahwa produk yang sesuai harapan dalam semua aspek akan mempengaruhi secara langsung kepuasan konsumen. Dari definisi diatas menunjukkan bahwa sejauh mana harapan konsumen terpenuhi memunculkan tingkat positif kepuasan konsumen yang tinggi sehingga tercipta hubungan yang positif diantara kualitas barang emas dan satisfaction consumen.

H1: Ada Pengaruh positif dan signifikan Kualitas barang terhadap Kepuasan Konsumen 


\section{Pengaruh Service Quality terhadap Kepuasan Konsumen}

Kualitas layanan yang sesuai keinginan, kebutuhan konsumen akan berdampak positif terhadap kepuasan konsumen, sehingga pada penelitian terdahulu kualitas layanan terhadap kepuasan konsumen jasa pada perusahaan swasta faisalabad berpengaruh positif dan signifikan. Dimensi kualitas layanan menurut parasuman et al (1988) yang sekarang telah di review ulang oleh tariq khalil (2013) ini menunjukkan kualitas layanan mampu untuk bersaing dan kinerja yang dirasakan melebihi harapan konsumen sehingga pada penelitian terdahulu di sector jasa swasta faisalabd menghasilkan hipotesis kualitas layanan berpengaruh positif dan signifikan. Dari penelitian terdahulu dapat ditarik hipotesa yaitu :

H2: Ada pengaruh positif Kualitas Pelayanan terhadap satisfaction consumen

\section{Pengaruh Kepuasan Konsumen terhadap WOM}

Kepuasan konsumen yang diterima individu tentunya akan berdampak positif, Adapun penelitian terdahulu oleh Prevista Fakhrun Nisa menyatakan bahwa pengaruh kepuasan konsumen berpengaruh positif dan signifikan terhadap WOM pada jasa bus putra mas kelas ekonomi, juga pada penelitian terdahulu yang diteliti oleh dhika amalia mengenai BPJS Ponorogo menghasilkan bahwa kepuasan konsumen mendorong orang untuk melakukan WOM sehingga dari penelitian tersebut kepuasan konsumen berpengaruh positif dan signifikan terhadap WOM BPJS Ponorogo. Dari penelitian diatas dapat diuraikan yaitu H3: Ada pengaruh positif Kepuasan Konsumen terhadap WOM

\section{Pengaruh Kualitas Layanan terhadap WOM}

Service Quality merupakan kunci keberhasilan perusahaan untuk memenangkan persaingan, namun semua perusahaan memiliki pemikiran yang sama sehingga banyak perusahaan jasa yang memiliki kualitas layanan yang serupa, hal ini menyebabkan kualitas layanan bukan merupakan kunci keberhasilan perusahaan satu - satunya. (Ayu, 2011). Perkembangan kualitas layanan saat ini semakin inovatif, konsumen yang semakin komunikatif memberikan feedback terhadap kualitas layanan yang diberikan melalui WOM.

Loannis E dalam penelitiannya "Service quality effect on satisfaction and word of mouth in the health care industry" membuktikan bahwa kualitas layanan pada dimensi emphati mempengaruhi secara langsung WOM namun pada dimensi lainnya emphatic memberikan pengaruh ke tangibles, tanggap dan jaminan sehingga kualitas layanan secara tidak langsung mempengaruhi WOM hal ini menciptakan hasil yang positif sehingga adanya pengaruh terhadap WOM.

H4: Ada pengaruh positif Kualitas Layanan terhadap WOM. 


\section{METODE PENELITIAN}

Jenis data yang digunakan adalah data primer dan data sekunder. Data primer adalah data yang dikumpulkan secara langsung yang dilakukan dilapangan berbentuk sikap, opini, atau pengalaman dari satu orang atau kelompok yang dilakukan oleh orang yang melakukan penelitian. Dalam pengisian kuesioner, responden diarahkan untuk menjawab beberapa pertanyaan seperti identitas responden, tanggapan responden dsb. Jawaban kuisioner pada penelitian ini dengan memberikan skala pengukuran ordinal. Skala ini membagi skor kedalam tujuh kotak, dimana skor satu untuk jawaban responden yang sangat tidak setuju atau rendah dan skor tujuh untuk jawaban responden yang tinggi. Agar lebih jelas dapat lihat contoh di bawah ini.

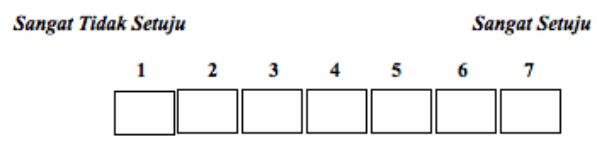

Sesuai dengan penjabaran pada telaah pustaka, terdapat enam belas indikator yang akan diukur dari total keseluruhan empat variabel. Empat variabel tersebut adalah Quality product yang terdiri dari 4 indikator variasi produk, desain perhiasan, kadar emas dan produk emas dapat diterima di toko lainnya, Quality Service terdiri dari 4 indikator yaitu daya tangkap yang baik, informasi akurat, berpenampilan menarik, pelayanannya ramah, Consumer Satisfaction memiliki 4 indikator diantaranya sesuai harapan, kejujuran, standar kualitas produk internasional, fasilitas dan yang terakhir adalah variable WOM yang memiliki 4 indikator.

Data sekunder pada penelitian ini diperoleh secara indirect melalui jurnal, berita, buku, laporan, karya ilmiah dan lembaga pemerintahan yang telah diterbitkan oleh pihak tertentu. Dengan harapan data sekunder ini dapat sebagai pendukung data primer yang dimana data tersebut menekankan pada kualitas dan kesesuaian peneliti dalam menggunakan dan memilihnya.

\section{Populasi dan Pengambilan Sampel}

\section{Populasi}

Populasi didefinisikan sebagai sekelompok individu yang memiliki kesamaan karakteristik tertentu yang membedakan kelompok dengan individu lainnya (Ferdinand, 2015). Keseluruhan populasi yang ada pada penelitian ini adalah konsumen yang melakukan transaksi di toko pusaka mas Sukorejo yang belum diketahui berapa konsumen yang melakukan pembelian setiap harinya. 


\section{Sampel}

Sampel merupakan part of population yang diharapkan mampu mewakili populasi dalam penelitian (Ferdinand, 2006). Metode pengambilan sampel dilakukan melalui metode non random sampling yaitu accidental sampling (sampling tanpa sengaja) dimana sampel dilakukan secara cepat pada konsumen yang melakukan pembelian produk emas di toko pusakamas Sukorejo pada hari itu.

Pengujian pada penelitian ini menggunakan sebuah alat yang dapat mengukur hubungan kausalitas yang terdapat dalam model kausal. Agar dapat memenuhi syarat dalam menggunakan alat analisis tersebut, maka sampel minimum ditentukan dengan mengalikan jumlah indikator dengan angka 5. Adapun sampel maksimum ditentukan dengan mengalikan jumlah indikator dengan angka 10. Perhitungan banyaknya sampel adalah sebagai berikut:

Sampel minimum = jumlah indikator dikali 5

$=16 \times 5$

$=80 \mathrm{~min}$

Sampel maksimum $=$ jumlah indicator $\times 10$

$=16 \times 10$

$=160 \max$

Berdasarkan metode SEM yang dijabarkan diatas maka jumlah sampel minimum adalah 80 responden dan sampel maksimum adalah 160 responden, namun untuk menghindari adanya respon rate yang rendah dan kemudahan hasil dalam pengolahan maka diputuskan akan diambil sample maksimum sebanyak 160 responden.

\section{Uji Validitas dan Reliabilitas Data}

\section{Uji Validitas}

Kuisioner dapat dikatakan valid ketika pertanyaan dalam kuisioner dapat mengungkapkan sudatu hal yang diukur melalui kuisioner itu sendiri (Ghozali,2012). Uji validitas dilakukan untuk mengklarifikasi setiap jawaban dari beberapa variabel dan indikator yang digunakan dalam model penelitian. Uji ini dilakukan dengan membandingkan nilai critical ratio dengan standard error. Indikator variabel dinyatakan valid apabila nilai estimasi critical ratio $2 x$ lebih besar dibandingkan nilai standard erromya.

\section{Uji Reliabilitas}

Konsistensi jawaban yang diberikan responden diukur. Sebuah data disebut reliabel apabila responden konsisten dalam menjawab pertanyaan yang ada pada kuesioner. Uji realibilitas juga dijadikan uji kusioner dari ukuran indicator dari sebuah variable yang digunakan rumus koefisien alpha Cronbach (ghozali,2012). Dimana 
bila hasil dari koefisien alpha $>$ dengan taraf signifikansi $70 \%$ atau 0,7 dapat dikatakan reliable dan apabila koefisien alpha $<$ dengan taraf signifikansi $70 \%$ atau 0,7 dapat dikatakan tidak realible.

\section{Teknik Analisis}

Analisis pada penelitian ini menggunakan Structural Equation Model (SEM). Adapun pemilihan penggunaan teknik ini berdasarkan kemampuannya dalam mengolah serta melakukan pengujian pada serangkaian hubungan yang ada pada model penelitian secara simultan walaupun relatif rumit.

Terdapat tujuh langkah dalam menggunakan SEM, yakni:

\section{Pengembangan model teoritis}

Langkah pertama yakni melakukan pengembangan sebuah model yang dilengkapi dengan dasar teori yang kuat. Kemudian model tersebut divalidasi secara empirik.

\section{Penyusunan diagram alur}

Diagram alur digunakan untuk menjelaskan hubungan kausalitas yang akan diuji dalam penelitian ini. Bentuk persamaan biasa digunakan untuk mengetahui hubungan-hubungan kausal. Terdapat dua kelompok yang membangun diagram alur, yaitu sebagai berikut:

\section{1) Konstruk Eksogen (Eksogenus Constructs)}

Konstruk tersebut menjelaskan suatu variabel yang tidak dapat diduga oleh variabel lain dalam model. Konstruk eksogen juga dikenal sebagai "independent variables" atau "source variables".

\section{2) Konstruk Endogen (Endogenus Construct)}

Konstruk endogen adalah faktor-faktor yang diprediksi oleh satu atau beberapa konstruk. Melalui konstruk ini, satu atau beberapa konstruk endogen lainnya dapat diprediksi, tetapi hanya hubungan kausal yang dapat terbentuk antara konstruk eksogen dengan konstruk endogen.

\section{Konversi alur ke dalam persamaan}

Pada tahap ini diagram alur dirubah kedalam model pengukuran. Persamaan yang dibuat dari diagram alur dikonversikan menjadi:

\section{1) Persamaan-persamaan struktural}

Persamaan ini disusun untuk memberikan peryataan pada suatu hubungan kausalitas terhadap berbagai konstruk. Pada persamaan stuktural dapat disusun sebagai berikut:

Variabel Endogen $=$ Variabel Eksogen + Variabel Endogen + Eror 


\section{2) Persamaan spesifikasi model pengukuran}

Pada tahap ini variabel yang mengukur konstruk harus ditentukan. Setelah itu serangkaian matriks yang menunjukkan korelasi yang dihipotesiskan antar konstruk atau variabel juga harus ditentukan seperti pada tabel 3.

\section{Memilih matriks input dan esimasi model}

Matriks input yang digunakan dalam penelitian ini berupa matriks kovarians. Adapun estmasi model yang digunakan yakni Maksimum Likelihood Estimation (MLE).

\section{Menilai problem identifikasi}

Problem identifikasi yakni ketidakmampuan atas suatu model yang digunakan untuk menghasilkan estimasi yang unik. Apabila setiap kali estimasi muncul problem identifikasi, maka sebaiknya mengembangkan lebih banyak konstruk atau model dipertimbangkan ulang.

\section{Evaluasi kriteria goodness-of-fit}

Pengujian terhadap kesesuaian pada model melalui kriteria goodness of fit dilakukan pada tahap ini. Beberapa indeks kesesuaian dan cut off value digunakan untuk melakukan pengujian pakah suatu model yang telah diajukan dapat diterima atau ditolak.

1) Melakukan evaluasi apakah asumsi-asumsi SEM sudah terpenuhi, yakni: ukuran, sampel, normalitas, linearitas outliers dan multikolinearitas dan similiaritas.

2) Melakukan uji kesesuaian yakni sebagai berikut:

\section{a. $\mathrm{X}^{2}$ Chi-Square Statistik}

Model yang diuji diterima apabila nilai chi squarenya sedikit. Semakin sedikit nilai x kuadrat maka semakin baik model yang digunakan dan diterima menurut profitabilitas dengan $p$ lebih besar dari 0.05 atau $p$ lebih besar dari 0.10 .

b. RMSEA (The Root Mean Square Error of Approximation)

RMSEA yakni nilai Goodness-of-Fit yang dapat diharapkan bila model diestimasi dalam populasi. Jika nilai RMSEA $\leq 0.08$ maka model dapat diterima.

c. GFI (Goodness-of-Fit Index)

GFI adalah ukuran non statistic yang memiliki range nilai 0.0 (poor fit) hingga 1.0 (perfect fit). Nilai yang tinggi dalam indeks ini menunjukkan sebuah "better fit". 


\section{d. AGFI (Adjust Goodness-of-Fit Index)}

AGFII dapat dianjurkan ketika Adjust Goodness of fit Index memiliki nilai $\geq$ 0.90 .

\section{e. CMIN/DF (The Minimum Sampel Discrepancy Function)}

CMIN/DF menunjukkan hasil pembagian chi square dengan $d f$ sehingga disebut $x$ kuadrat relatif. Nilai $x$ kuadrat relatif yang diterima adalah $\leq 2.0$ atau 3.0, maka hal tersebut merupakan indikasi yang berasal dari acceptable fit diantara model dan data.

\section{f. TLI (Tucker Lewis Index)}

TLI menunjukkan alternatif angka perbandingan suatu model yang diuji dengan sebuah base line model. Adapun hasil TLI yang diterima dari suatu model adalah $\geq 0.95$ menunjukan better fit.

\section{g. CFI (Comparative Fit Index)}

Nilai CFI adalah $\geq 0.95$ menunjukkan hasil kesesuaian yang tidak dipengaruhi oleh banyaknya sampel. Jika nilai CFI semakin mendekati satu maka model semakin baik atau menunjukkan better fit.

\section{Interpretasi dan modifikasi model}

Interpretasi dilakukan dengan melihat hasil pengujian. Suatu model yang diestimasi dikatakan baik apabila residualnya sedikit atau mendekati 0 dan distribusi kovarian residualnya simetris. Secara statistik batas nilai pada tingkat 5\% yang diperkenankan untuk diinterpretasikan sebagai signifikan secara statistik adalah 1,96 .

\section{Tabel 3}

\section{Persamaan dalam Penelitian}

\begin{tabular}{cc}
\hline Konstruk Eksogen & Konstruk Endogen \\
\hline $\mathrm{X} 1.1=\Lambda 1$ Kualitas Barang $+\mathrm{d} 1$ & $\mathrm{Y} 1.1=\Lambda 9$ Kepuasan Konsumen $+\mathrm{e} 9$ \\
$\mathrm{X} 1.2=\Lambda 2$ Kualitas Barang $+\mathrm{d} 2$ & $\mathrm{Y} 1.2=\Lambda 10$ Kepuasan Konsumen + \\
$\mathrm{X} 1.3=\wedge 3$ Kualitas Barang $+\mathrm{d} 3$ & $\mathrm{e} 10$ \\
$\mathrm{X} 1.4=\Lambda 4$ Kualitas Barang $+\mathrm{d} 4$ & $\mathrm{Y} 1.3=\Lambda 12 \mathrm{Kepuasan}$ Konsumen + \\
$\mathrm{X} 2.1=\wedge 5$ Kualitas Pelayanan $+\mathrm{d} 5$ & $\mathrm{e} 12$ \\
$\mathrm{X} 2.2=\Lambda 6$ Kualitas Pelayanan $+\mathrm{d} 6$ & $\mathrm{Y} 1.4=\Lambda 13 \mathrm{Kepuasan} \mathrm{Konsumen} \mathrm{+}$ \\
$\mathrm{X} 2.3=\Lambda 7$ Kualitas Pelayanan $+\mathrm{d} 7$ & $\mathrm{e} 13$ \\
$\mathrm{X} 2.4=\Lambda 8$ Kualitas Pelayanan $+\mathrm{d} 8$ & $\mathrm{Y} 2.1=\Lambda 14 \mathrm{WOM}+\mathrm{e} 14$ \\
& $\mathrm{Y} 2.2=\Lambda 15 \mathrm{WOM}+\mathrm{e} 15$ \\
& $\mathrm{Y} 2.3=\Lambda 16 \mathrm{WOM}+\mathrm{e} 16$ \\
& $\mathrm{Y} 2.4=\Lambda 17 \mathrm{WOM}+\mathrm{e} 17$ \\
\hline
\end{tabular}




\section{Gambar 2}

\section{Diagram Alur Model Penelitian}

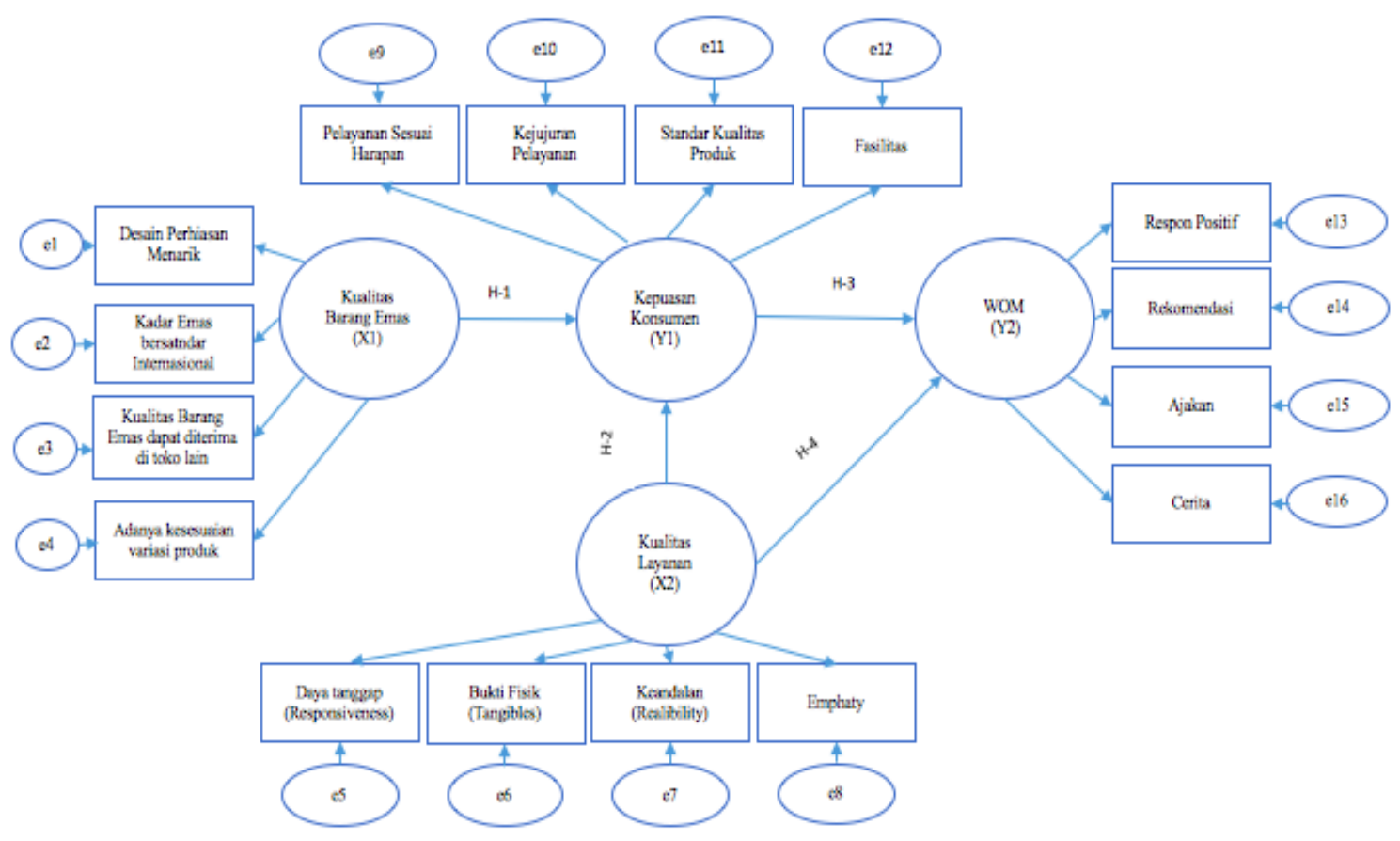

\section{HASIL PENELITIAN DAN PEMBAHASAN}

\section{Gambaran Umum Responden}

Responden Berdasarkan Jenis Kelamin

Diagram gambar jenis kelamin dapat dilihat responden pria sebanyak 30 orang dengan presentasi $20 \%$ dan responden perempuan yang mendominasi berjumlah 125 orang dengan presentase $80 \%$ Dari total 155 responden. Berdasarkan tabel tersebut, responden di dominasi oleh kaum hawa. Hal ini terjadi karena mayoritas yang melakukan transaksi di toko emas pusaka Sukorejo Kendal pengunjungnya adalah wanita. responden dalam penelitian ini merupakan pengunjung toko emas Pusaka Mas Sukorejo Kendal.

\section{Gambar 4}

Responden Menurut Jenis Kelamin

\begin{tabular}{ccc}
\hline Jenis Kelamin & Frekuensi & Presentase \\
\hline Pria & 30 & 0.20 \\
Wanita & 125 & 0.80 \\
\hline Jumlah & 155 & 100
\end{tabular}

Sumber: Responden Pusaka Mas, 2018 
Responden Menurut Usia

Gambaran responden berdasarkan usia yang telah tercatat dalam pengisian kuisioner, dapat dilihat bahwa responden dengan rentang usia 22-27 tahun dengan presentase sebesar $62.5 \%$ dari total 155 responden.

Tabel 5

Responden Berdasarkan Jenis Umur

\begin{tabular}{ccc}
\hline Usia & Jumlah Responden & Presentase \\
\hline$<21$ & 11 & 7 \\
$21-27$ & 97 & 62.5 \\
$27-35$ & 41 & 26.4 \\
$>35$ & 6 & 4.1 \\
\hline Jumlah & 155 & 100 \\
\hline
\end{tabular}

Sumber :Data Responden Pusaka Mas, 2018

\section{Responden Berdasarkan Jenjang Pendidikan}

Gambaran responden berdasarkan jenjang pendidikan akan ditampilkan pada tabel berikut, dimana diketahui bahwa responden terbanyak berasal dari jenjang pendidikan SMA sebanyak $83.23 \%$ berjumlah 129 orang dan diposisi terendah pada angka $1.31 \%$ yaitu berjenjang D3

\section{Tabel 6}

\section{Responden Berdasarkan Jenjang Pendidikan}

\begin{tabular}{ccc}
\hline Pendidikan Terakhir & Jumlah Responden & Presentase \\
\hline SMP & 7 & 4.5 \\
SMA & 129 & 83.23 \\
S1 & 14 & 9.03 \\
S2 & 3 & 1.93 \\
D3 & 2 & 1.31 \\
\hline Jumlah & 155 & 100
\end{tabular}

Sumber: Data Responden Pusaka Mas, 2018

\section{Responden Berdasarkan Frekuensi Kunjungan}

Gambaran responden berdasarkan frekuensi kunjungan ke toko emas pusaka mas Sukorejo Kendal dalam waktu sebulan akan ditampilkan pada tabel frekuensi kunjungan, diketahui mayoritas responden mengunjungi toko emas pusakamas Sukorejo sebanyak $1 \mathrm{x}$ dan 4 sampai $8 \mathrm{x}$ dalam kurun waktu sebulan sebesar $32.9 \%$ dan $25.8 \%$ dari total 155 responden. 


\section{Tabel 7}

Responden Berdasarkan Frekuensi Kunjungan

\begin{tabular}{ccc}
\hline Frekuensi Kunjungan & Frekuensi & Prosentase \\
\hline $1 \mathrm{x}$ & 51 & 32.9 \\
$1-4 \mathrm{x}$ & 34 & 21.9 \\
$4-8 \mathrm{x}$ & 40 & 25.8 \\
$>10 \mathrm{x}$ & 30 & 19.4 \\
\hline Jumlah & 155 & 100
\end{tabular}

Sumber: Data Responden Pusaka Mas, 2018

\section{Uji Validitas dan Reliabilitas}

Berdasarkan hasil dari pengujian validitas dengan menggunakan correlate bivariate dikatakan valid apabila masing-masing variabel dan indikatornya menunjukkan nilai lebih besar dari 0.4. Data kuisioner dikatakan validity apabila nilai lebih besar dari 0.4 dari masing - masing variable dan indikatornya, hal ini ditunjukkan dari nilai pearson correlation. Pengujian reliabilitas pada setiap variable dan indicator pembentukannya bahwa setiap variable dan indikatornya memperlihatkan ukuran yg reliabel. Hal tersebut terjadi karena Cronbach alpha $>0,6$. Maka dapat dikatakan kuisioner tersebut masih layak digunakan.

\section{Analisis Structural Equation Modelling}

\section{Gambar 3}

Hasil Pengujian Structural Equation Model (SEM)

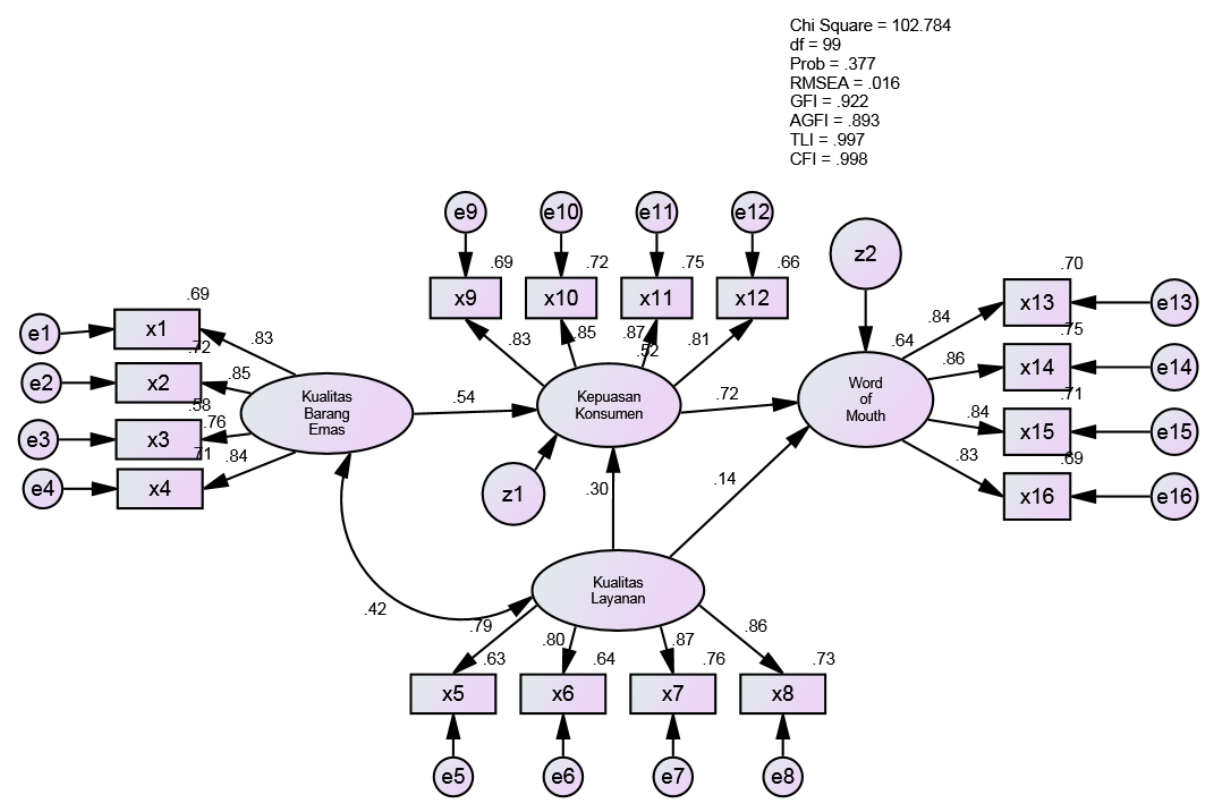


Berdasarkan Hasil uji SEM, diperoleh nilai R Square sebesar 0,64, dimana word of mouth dipengaruhi oleh kepuasan konsumen, kualitas barang emas, kualitas layanan sebesar 64\% sisanya 36\% dipengaruhi variabel lain yang tidak diujikan. Model hipotesis pada penelitian ini sudah sesuai dengan data atau fit berdasarkan hasil pengujiaannya, seperti pada tabel 8:

\section{Tabel 8}

Hasil Pengujian Kelayakan Model Structural Equation Model (SEM)

\begin{tabular}{cccc}
\hline $\begin{array}{c}\text { Goodness of Fit } \\
\text { Indeks }\end{array}$ & Cut-off Value & Hasil Analisis & Evaluasi Model \\
\hline Chi-Square & $<162.738$ & 102,784 & Baik \\
Probability & $\geq 0.05$ & 0,377 & Baik \\
RMSEA & $\leq 0.08$ & 0,016 & Baik \\
GFI & $\geq 0.90$ & 0,922 & Baik \\
AGFI & $\geq 0.90$ & 0,893 & Marginal \\
TLI & $\geq 0.95$ & 0,967 & Baik \\
CFI & $\geq 0.95$ & 0,996 & Baik \\
\hline
\end{tabular}

Berdasarkan Tabel 8, disebutkan bahwa nilai chi square kelayakan model SEM sudah baik, dimana nilai chi square sebesar 102.784 yang lebih kecil dari chi square table 162.738. Namun pada nilai AGFI sebesar 0.893 dimana lebih kecil dari standar nilai lebih dari 0.90 dengan nilai model marginal. Dapat dikatakan bahwa variable yang dipakai tidak sesuai rekomendasi, namun nilai tersebut mendekati rekomendasi sehingga evaluasi model masih layak dilanjutkan (Hair et al,1998). Agar dapat memberikan jawaban atas hipotesis yang diajukan, dibutuhkan uji stastistik pada hubungan antar variable yang akan dipakai sebagai landasan. Model SEM juga dapat menggambarkan signifikansi hubungan antar variable dengan nilai probability $(p)$ dan Critical Ratio $(\mathrm{CR})$ agar lebih jelasnya dapat dilihat pada table berikut ini.

\section{KESIMPULAN DAN IMPLIKASI}

\section{Kesimpulan}

Analisis data yang telah dilakukan memiliki 4 simpulan hipotesis antara lain: (1) Hasil penelitian $\mathrm{H} 1$ ditemukan adanya pengaruh positif antara kualitas barang emas terhadap kepuasan konsumen, dapat dikatakan semakin tinggi kualitas emas akan meningkatkan kepuasan konsumen toko emas pusaka Sukorejo Kendal. Pada subjek penelitian toko emas pusaka masing - masing indicator mampu menyajikan kualitas barang emas yang dapat memuaskan konsumen seperti perhiasan yang menarik, adanya sertifikasi internasional dan lainnya sehingga dapat memikat konsumen untuk mengunjungi toko lebih dari sekali; (2) Hipotesis H2 diterima 
karena adanya kualitas layanan yang berpengaruh positif terhadap kepuasan konsumen oleh responden, kualitas layanan yang baik dari toko emas pusaka mas Sukorejo dapat meningkatkan keunggulan kepuasan konsumen; (3) Hipotesis H3 ditemukan adanya pengaruh positif antara kepuasan konsumen terhadap WOM. Semakin tinggi kepuasan konsumen akan membantu meningkatkan WOM toko emas pusaka mas Sukorejo Kendal dimana hal itu dilakukan oleh konsumen toko emas yang merasa puas. Maka hipotesis H3 dinyatakan diterima; (4) Hipotesis mengenai kualitas layanan yang secara langsung mempengaruhi WOM menunjukkan hasil yang positif, sehingga dapat dikatakan kualitas layanan yang semakin tinggi akan membantu konsumen dalam melakukan WOM. Maka hipotesis H4 dinyatakan diterima.

\section{Keterbatasan Penelitian}

Keterbatasan penelitian yang dapat ditarik dari penelitian ini adalah sebagai berikut: (1) Variabel yang diteliti hanya 3 jenis variabel yang mempengaruhi WOM yaitu Kualitas Barang emas, kualitas layanan dan kepuasan pelanggan; (2) Hasil penelitian ini tidak dapat digeneralisasi pada kasus lain diluar obyek penelitian ini yaitu: Toko pusaka mas Sukorejo; (3) Keterbatasan peneliti untuk menjangkau toko emas lain yang ada di Sukorejo Kendal.

\section{Agenda Penelitian Mendatang}

Agenda penelitian mendatang adalah sebagai berikut: (1) Memberikan tambahan variabel independen yang dapat mempengaruhi WoM; (2) Peneliti dapat membandingkan dengan toko emas lainnya yang berada di Sukorejo agar tidak hanya terfokus pada satu toko emas saja: (3) Penelitian dapat menjangkau kecamatan / kabupaten lain di luar Sukorejo.

\section{REFERENSI}

Ammari, N. (2012). The Effects of Loyalty Program Quality on Word -of -Mouth Recommendations Intentions. World Academy of Science, Engineering and Technology, 64(4), 1002-1011. Retrieved from http://waset.org/publications/14651/the-effects-of-loyalty-program-quality-onword-of-mouth-recommendations-intentions

Anderson, E. W. (1998). Customer Satisfaction and WOM. Service Research, 1(1), 5-17.

Anita. (2015). Analisis Komparasi Investasi Logam Mulia Emas Dengan Saham Perusahaan Pertambangan Di Bursa Efek Indonesia 2010-2014, 5(2), 243252. 
Asteria, D. K. (2018). Perhiasan Cincin Jadi Pilihan Anak Muda. Retrieved from https://lifestyle.bisnis.com/read/20180417/104/785535/perhiasan-

Athiyah, L. (2016). Product's Quality and Its Impact on Customer Satisfaction A field study in Diwaniyah Dairy Factory. Proceedings of the 10th International Management Conference, 57-65. Retrieved from http://conferinta.management.ase.ro/archives/2016/PDF/1_7.pdf

Bahri-ammari, N. (2012). Pengaruh Kualitas Loyalty Program Firman -dari Rekomendasi -Mouth niat, 6(1), 619-628.

Bharwana, T. K., \& Mohsin, M. (2013). Impact of Service Qua lity on Customers ' Satisfaction: A Study from Service Sector especially Private Colleges of. International Journal of Scientific and Research Publications, 3(5), 1-7. https://doi.org/10.1016/j.geoderma.2012.02.011

Chaniotakis, I. E., \& Lymperopoulos, C. (2009). Service quality effect on satisfaction and word of mouth in the health care industry. Managing Service Quality, 19(2), 229-242. https://doi.org/10.1108/09604520910943206

Febrian, A. (2018). Emas Batangan Laris Manis, Bagaimana Emas Perhiasan? Kontan.Co.ld. Retrieved from https://lifestyle.kontan.co.id/news/emasbatangan-laris-manis-bagaimana-permintaan-emas-perhiasan

Ferdinand, A. (2013). Metode Penelitian Manajemen. Semarang: Badan Penerbit Universitas Diponegoro.

Imam, G. (2013). Aplikasi Analisis Multivariate dengan Program SPSS. Semarang: Badan Penerbit Universitas Diponegoro.

Kotler, P. (2009). Marketing Manajemen. (Erlangga, Ed.). jakarta.

Kusnandar, R. (2010). Cara Cerdas Berkebun Emas. jakarta: Trans Media Pustaka.

Leonnard, S., Comm, M., \& Thung, F. (2017). The relationship of service quality, word-of-mouth, and repurchase intention in online transportation services. Journal of Process Management. New Technologies, 5(4), 30-40. https://doi.org/10.5937/jouproman5-15210

Muhammad Awan, H., Shahzad Bukhari, K., \& lqbal, A. (2011). Service quality and customer satisfaction in the banking sector: A comparative study of conventional and Islamic banks in Pakistan. Journal of Islamic Marketing, 2(3), 203-224. https://doi.org/10.1108/17590831111164750

Muhammad Tahir Jan, Kalthom Abdullah:, \& Ali Shafiq. (2013). The Impact of Customer Satisfaction on Word-of-Mouth. International Journal of Information Technology \& Computer Science, 10(3), 10. 
Mulyanto. (2017). The Influence of Product Quality, Service Quality and Trust on Customer Satisfaction and Its Impact on Customer Loyalty (Case Study PT ABC Tbk). International Journal of Scientific \& Engineering Research, 8(7), 2330-2336.

Ngo, M. V., \& Nguyen, H. H. (2016). The Relationship between Service Quality, Customer Satisfaction and Customer Loyalty: An Investigation in Vietnamese Retail Banking Sector. Journal of Competitiveness, 8(2), 103-116. https://doi.org/10.7441/joc.2016.02.08

Novalius, F. (2017). Beli Emas Kena Pajak, Penjualan Antam Tak Turun. Okezone.Com. Retrieved from https://economy.okezone.com/read/2017/10/06/320/1789885/beli-emas-kenapajak-antam-sebut-penjualan-tak-turun

Pelayanan, H. K., \& Dibeli, D. A. N. (2017). Hubungan kualitas pelayanan, kataofmouth, dan dibeli kembali niat di online layanan transportasi, 5(4), 30-40.

Produk, K., Dampaknya, D. A. N., \& Kepuasan, T. (2016). Studi pentingnya Asumsi Penelitian Ada keterkaitan dengan indikasi statistik antara kualitas produk dan kepuasan pelanggan eksternal Ada hubungan, 57-65.

Taghizadeh, H., Taghipourian, M. J., \& Khazaei, A. (2013). The effect of customer satisfaction on word of mouth communication. Research Journal of Applied Sciences, Engineering and Technology, 5(8), 2569-2575. https://doi.org/10.19026/rjaset.5.4698

Triatmanto, B., \& Merdeka, U. (2016). Dampak Kualitas Produk dan Harga Nasabah Kepuasan dengan Mediator dari Customer Value, 30(2012), 59-68. 